\title{
Long-Lasting Plasticity of Hippocampal Adult-Born Neurons
}

\author{
Valérie Lemaire, ${ }^{1,2 *}$ Sophie Tronel, ${ }^{1,2 *}$ Marie-Françoise Montaron, ${ }^{1,2 *}$ Annabelle Fabre, ${ }^{1,2}$ Emilie Dugast, ${ }^{1,2}$ \\ and Djoher Nora Abrous ${ }^{1,2}$ \\ ${ }^{1}$ Institut National de la Santé et de la Recherche Médicale and ²Université Bordeaux, Neurocentre Magendie, Physiopathologie de la Plasticité Neuronale, \\ Unité 862, F-33000 Bordeaux, France
}

Adult neurogenesis occurs in the dentate gyrus of the hippocampus, which is a key structure in learning and memory. It is believed that adult-born neurons exert their unique role in information processing due to their high plasticity during immature stage that renders them malleable in response to environmental demands. Here, we demonstrate that, in rats, there is no critical time window for experience-induced dendritic plasticity of adult-born neurons as spatial learning in the water maze sculpts the dendritic arbor of adult-born neurons even when they are several months of age. By ablating neurogenesis within a specific period of time, we found that learning was disrupted when the delay between ablation and learning was extended to several months. Together, these results show that mature adult-born neurons are still plastic when they are functionally integrated into dentate network. Our results suggest a new perspective with regard to the role of neo-neurons by highlighting that even mature ones can provide an additional source of plasticity to the brain to process memory information.

\section{Introduction}

Scientists have asserted that, once development ends, the adult brain comprises a fixed number of neurons that no longer regenerate. This dogma has been challenged by the discovery that new neurons are produced throughout adulthood in a few brain areas. The dentate gyrus (DG) of the hippocampus, a key structure in learning and memory, is one region where neurogenesis occurs. Neurogenesis is a multistep process starting with the proliferation of neural precursors (Abrous et al., 2005). Within a few days following birth, at least $50 \%$ of the daughter cells die. Within 2 months, the surviving neurons receive inputs (van Praag et al., 2002; Piatti et al., 2006), form functional synapses with their target cells (Toni et al., 2008), and exhibit electrophysiological properties indistinguishable from those of mature neurons (Ge et al., 2007). These adult-born neurons are integrated into existing networks and play an important role in spatial memory (Dupret et al., 2008; Farioli-Vecchioli et al., 2008; Zhang et al., 2008; Garthe et al., 2009).

During immature stages, new neurons exhibit lower activation threshold and increased long-term potentiation (LTP) po-

\footnotetext{
Received Sept. 15, 2011; revised Dec. 6, 2011; accepted Dec. 28, 2011

Author contributions: V.L., S.T., and D.N.A. designed research; V.L., S.T., M.-F.M., A.F., and E.D. performed research; V.L., S.T., M.-F.M., and D.N.A. analyzed data; D.N.A. wrote the paper.

This work was supported by Institut National de la Santé et de la Recherche Médicale, University of Bordeaux 2, Région Aquitaine, le Plan Alzheimer, and Agence Nationale pour la Recherche (D.N.A.). A.F. was a recipient of a "La Fondation pour la Recherche Médicale Aquitaine" fellowship. We thank Dr. M. Koehl (Institut National de la Santé et de la Recherche Médicale Unité 862) for useful discussion and comments and Dr. F. H. Gage for the gift of GFP recombinant retrovirus. We greatly acknowledge V. Guyonnet Duperat for lentiviral vector production (Vectorology Platform of Structure Federative de Recherche TransBioMed Bordeaux), C. Dupuy, S. Rey, E. Ladeveze, and A. Mangin for their technical help.

*V.L., S.T., and M.-F.M. contributed equally to this work.

Correspondence should be addressed to Dr. Djoher Nora Abrous, Institut National de la Santé et de la Recherche Médicale, Neurocentre Magendie, Physiopathologie de la Plasticité Neuronale, Unité 862, F-33000 Bordeaux, France. E-mail: nora.abrous@inserm.fr.

DOI:10.1523/JNEUROSCI.4731-11.2012

Copyright $\odot 2012$ the authors $\quad 0270-6474 / 12 / 323101-08 \$ 15.00 / 0$
}

tential compared with mature DG neurons (Snyder et al., 2001; Schmidt-Hieber et al., 2004; Ge et al., 2007). Their high plasticity renders them malleable in response to environmental demands (Kempermann et al., 1997; Tashiro et al., 2007) and in particular to learning experience. Indeed, spatial learning was shown to promote the survival of newborn cells generated 1 week earlier (Gould et al., 1999; Dupret et al., 2007), to accelerate the differentiation of selected newborn cells toward a neuronal phenotype, and to increase the development of their dendritic tree (Tronel et al., 2010). It is believed that these plastic properties during a critical time window of their development confer upon them a unique role in processing new information (Deng et al., 2010). Then because they become unexcitable as they mature, they are thought to go for early retirement (Alme et al., 2010). However, adult-born neurons survive several months (Kempermann et al., 2003) during which they continue to develop (van Praag et al., 2002; Toni et al., 2008; Tronel et al., 2010). For these reasons, here we asked whether mature neo-neurons are still plastic and, if so, whether they are still required for spatial learning.

To address this issue, newborn neurons were labeled with an analog of thymidine [5-bromo- $2^{\prime}$-deoxyuridine (BrdU)] or with a retrovirus produced by the vector CAG-GFP (Zhao et al., 2006) 2 or 4 months before spatial learning in the water maze. To ascertain that mature adult-born cells are functionally relevant to learning experience, we used a lesion approach allowing ablation of adult-born neurons within a specific time window.

\section{Materials and Methods}

Animals. Adult male rats ( $n=146$; OFA; Charles River) weighing between 280 and $300 \mathrm{~g}$ ( 2 months of age) on delivery were used for these experiments. They were individually housed in standard cages under a $12 \mathrm{~h} \mathrm{light/dark} \mathrm{cycle} \mathrm{with} \mathrm{ad} \mathrm{libitum} \mathrm{access} \mathrm{to} \mathrm{food} \mathrm{and} \mathrm{water.} \mathrm{All} \mathrm{exper-}$ iments were performed in accordance with the recommendations of the European Union (86/609/EEC) and the French National Committee $(87 / 848)$. 
Table 1. Summary of the experimental groups and experiments

\begin{tabular}{|c|c|c|c|c|c|}
\hline Batch & Experiment & $\begin{array}{l}\text { Time between injections } \\
\text { and training }\end{array}$ & BrdU dose (mg/kg) & Group size & $\begin{array}{l}\text { Time of killing } \\
\text { after training }\end{array}$ \\
\hline 1 & Neo-neurons arborization & 2 months & 50 & $\begin{array}{l}\text { Control, } 6 \\
\text { Learning, } 8\end{array}$ & $1 d$ \\
\hline 3 & Neurons arborization & 4 months & & $\begin{array}{l}\text { Control, } 5 \\
\text { Learning, } 5\end{array}$ & $1 d$ \\
\hline 5 & $\begin{array}{l}\text { Effect of AraC infusion on cell proliferation measured } \\
2 \text { weeks after the end of the treatment }\end{array}$ & & $3 \times 50$ & $\begin{array}{l}\mathrm{aCSF}, 6 \\
\mathrm{AraC}, 6\end{array}$ & \\
\hline 6 & $\begin{array}{l}\text { Blockade of cell proliferation by AraC infusion } 2 \\
\text { months before training }\end{array}$ & 2 months & $3 \times 100$ & $\begin{array}{l}\mathrm{aCSF}, 13 \\
\mathrm{AraC}, 13\end{array}$ & $90 \mathrm{~min}$ \\
\hline
\end{tabular}

Intracerebroventricular surgery. One week after their arrival, guide cannulae were implanted into the lateral ventricles as previously described (Dupret et al., 2007). After 1 week of recovery, $6 \mu \mathrm{l}$ (per infusion site) of vehicle [artificial CSF (aCSF)] or of cytosine $\beta$-D-arabinofuranoside (Ara-C) (Sigma-Aldrich; at a concentration of $0.2,0.6$, or $1 \mathrm{mg} / 6 \mu \mathrm{l}$ ) solution was infused at a constant rate $(3 \mu \mathrm{l} / \mathrm{min})$. Infusions were repeated for 7 consecutive days.

BrdU injections. Rats were injected with BrdU (24 h apart) at different times before training (Table 1). The different age-matched control groups were injected within the same period.

Retrovirus-mediated labeling of new neurons. The murine Moloney leukemia virus-based retroviral vector CAG-GFP has been previously described (Zhao et al., 2006; Tronel et al., 2010) and is a gift from Drs. Gerald Pao and Inder Verma (Salk Institute, La Jolla, CA).

Lentivirus-mediated labeling of neurons. The lentivirus based-lentiviral vector, pTRIPAU3-MND-Dsred2-WPRE (Dsred2-LV), was produced by transient transfection of $293 \mathrm{~T}$ cells according to standard protocols (Sena-Esteves et al., 2004).

Water maze training. Rats were tested in the water maze at different times after BrdU injections (Table 1) as previously described (Dupret et al., 2007). The apparatus consisted of a circular swimming plastic pool (180 cm diameter, $60 \mathrm{~cm}$ height) that was filled with water $\left(20 \pm 1^{\circ} \mathrm{C}\right)$ that was rendered opaque by the addition of a white cosmetic adjuvant. Before training, animals were habituated to the pool for $2 \mathrm{~d}$ for 1 min per day. During training, the learning group (L) was composed of animals that were required to locate the submerged platform, which was hidden $1.5 \mathrm{~cm}$ under the surface of the water in a fixed location, using the spatial cues available within the room. Rats were all trained for four trials per day (90 s with an intertrial interval of $30 \mathrm{~s}$ and released from three different start points that varied randomly each day). If an animal failed to locate the platform, it was placed on that platform at the end of the trial. The time to reach the platform was recorded using a video camera that was secured to the ceiling of the room and connected to a computerized tracking system (VideoTrack; Viewpoint).

A detailed analysis of swim paths made to reach the platform location during learning was performed as previously described using the Wintrack software (http://www.dpwolfer.ch/wintrack). The following parameters were examined: (1) the cumulative search error corresponding to the difference between observed cumulative distance and minimal cumulative distance, and (2) path efficiency index corresponding to the percentage of path traveled within a deviation by $15^{\circ}$ or less of the direction of movement from the direction pointing to the goal.

Immunohistochemistry. Trained animals were killed $1 \mathrm{~d}$ or $90 \mathrm{~min}$ after the last trial (Table 1). The different age-matched control groups were killed within the same period. Free-floating sections $(50 \mu \mathrm{m})$ were pro- cessed in a standard immunohistochemical procedure to visualize BrdU (1:200; Dako), eGFP (1:500; BD Biosciences Pharmingen), Ki67 (1:800; Novocastra), Dcx (1:1000; Santa Cruz Biotechnology), on alternate 1-in-10 sections (Dupret et al., 2007; Tronel et al., 2010). The numbers of immunoreactive (IR) cells throughout the entire granular layer of the supragranular and infragranular blades of the DG were estimated using the optical fractionator method (Dupret et al., 2007). Results are expressed as the total number of IR cells per DG (both side).

The morphometric analysis of virus-labeled neurons was performed with a $100 \times$ objective using a semiautomatic neuron tracing system (Neurolucida; MicroBrightField) as previously described (Tronel et al., 2010). Data for various metric measurements were calculated, including the cell body area, number of dendritic nodes, number of dendritic ends, and total dendritic length. Data shown were from a minimal of 10 neurons per rat from at least four animals for each condition (Table 1). For spines analysis, images of GFP-IR dendritic processes (40 $\mu \mathrm{m}$ segment) were acquired at $0.2 \mu \mathrm{m}$ intervals with a SPE confocal system and analyzed with the Volocity software (Improvision) as previously described (Tronel et al., 2010). One segment per neuron and 10 neurons per animal were analyzed for each animal at each time point. Data show results from at least 40 individual GFP+ segments from at least four animals per condition.

Statistical analysis. Data (mean \pm SEM) were analyzed using a Student's t test or using ANOVA, which was followed by the Fisher test when necessary.

\section{Results}

Spatial learning increases the complexity of the dendritic arbor of mature adult-born neurons

We and others have shown that spatial learning regulates the survival and the dendritic development of immature neurons generated 1 week before testing animals in the water maze using the classic protocol of reference memory (Gould et al., 1999; Dupret et al., 2007). These changes were specific to learning since the development of the dendritic arbor of immature neurons was not influenced by physical activity/stress (dendritic length: control, $n=4: 148.57 \pm 20.16$; yoked group, $n=4: 152.79 \pm 11.74$; $\left.t_{(6)}=-0.88, p=0.41\right)$ or by learning to find a visible platform (control, $n=4: 160.97 \pm 24.51$; visible platform, $n=4: 112.74 \pm$ $\left.16.10 ; t_{(6)}=1.64, p=0.15\right)$, a task that does not require the hippocampus (Morris et al., 1982). Here, we asked whether the remodeling ability of newborn neurons in response to spatial learning can be extended beyond the immature stage. We labeled 
a

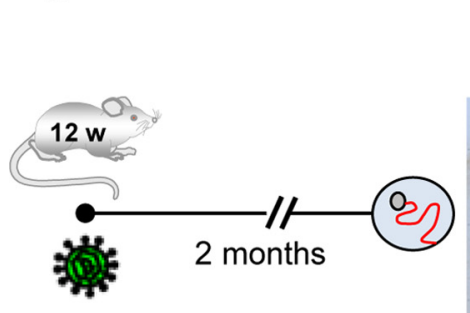

b

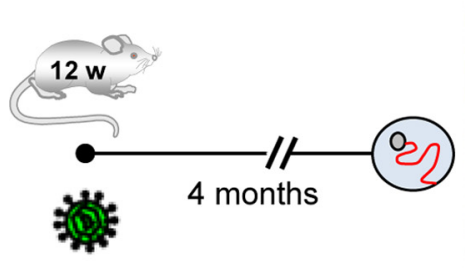

C

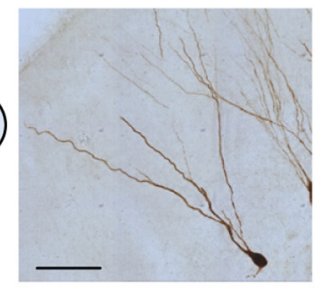

d

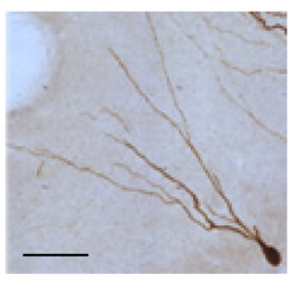

e

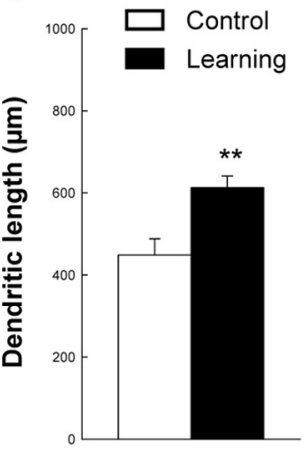

f

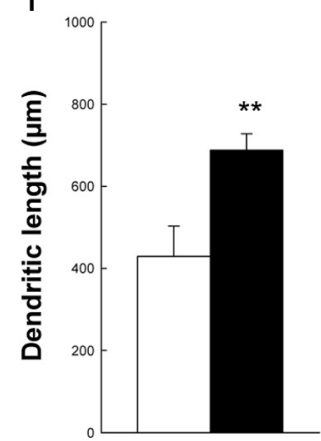

g

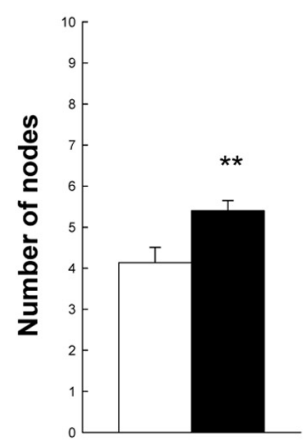

h

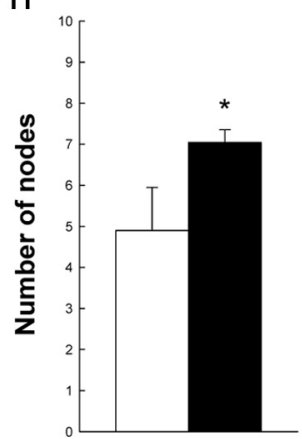

i

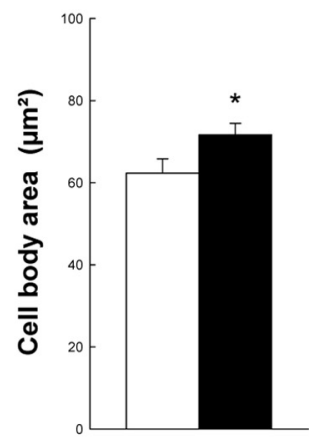

j

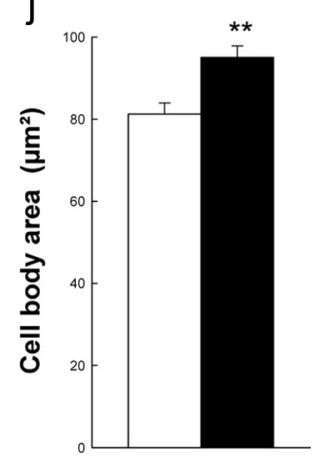

Figure 1. Influence of spatial learning on the dendritic arbor complexity of neo-neurons generated 2 months (top) or 4 months (bottom) before learning. $\boldsymbol{a}, \boldsymbol{b}$, Experimental designs. $\boldsymbol{c}$, $\boldsymbol{d}$, Representative examples of 2-month-old (c) and 4-month-old (d) adult-born neurons labeled with a GFP retrovirus. Scale bar, $50 \mu \mathrm{m}$. Spatial learning increases the dendritic length (e, $\boldsymbol{f})$, the number of nodes $(\boldsymbol{g}, \boldsymbol{h})$, and the size of the cell bodies $(\boldsymbol{i}, \boldsymbol{j})$ of adult-born neurons. ${ }^{* *} p \leq 0.01$ compared with age-matched control groups. $C$, Control $(2$ months: $n=6 ; 4$ months: $n=4) ; L, l$ learning (2 months: $n=8 ; 4$ months: $n=6$ ). Error bars indicate SEM.

Table 2. Influence of spatial learning on the dendritic arbor and the survival of mature adult-born neurons

\begin{tabular}{lccl}
\hline Age of neo-neurons & Control & Learning & Significance \\
\hline 2 months of age & & & \\
Dendritic length & $448.48 \pm 39.28$ & $612.77 \pm 28.91$ & $t_{(12)}=-3.45, p=0.005$ \\
No. of nodes & $4.14 \pm 0.37$ & $5.40 \pm 0.25$ & $t_{(12)}=-2.96, p=0.01$ \\
No. of endings & $5.17 \pm 0.38$ & $6.44 \pm 0.24$ & $t_{(12)}=-2.97, p=0.01$ \\
Cell body area & $62.32 \pm 3.51$ & $71.71 \pm 2.75$ & $t_{(12)}=-2.14, p=0.05$ \\
BrdU-IR cell no. & $2325 \pm 408$ & $2605 \pm 209$ & $t_{(10)}=0.61, p=0.55$ \\
4 months of age & & & \\
Dendritic length & $429.52 \pm 73.35$ & $693.02 \pm 39.93$ & $t_{(8)}=-3.51, p=0.007$ \\
No. of nodes & $4.90 \pm 1.05$ & $7.07 \pm 0.31$ & $t_{(8)}=-2.38, p=0.04$ \\
No. of endings & $5.99 \pm 1.07$ & $8.28 \pm 0.33$ & $t_{(8)}=-2.40, p=0.04$ \\
Cell body area & $81.23 \pm 2.72$ & $95.06 \pm 2.78$ & $t_{(8)}=-3.51, p=0.007$ \\
BrdU-IR cell no. & $1964 \pm 608$ & $2040 \pm 295$ & $t_{(8)}=-0.11, p=0.91$ \\
\hline
\end{tabular}

the newborn neurons by injecting animals with BrdU and by infecting the DG region with a retrovirus produced by the vector CAG-GFP (Zhao et al., 2006) (Fig. 1). Two or 4 months later, animals were trained in the water maze using the reference memory protocol (Table 1, batches 1-2). Animals were killed when an asymptotic level of performance was reached as previously described (Döbrössy et al., 2003; Dupret et al., 2007; Tronel et al., 2010).

The analysis of the morphology of GFP-labeled neo-neurons indicated that spatial learning increased their dendritic length, the number of dendritic nodes and ends, as well as the size of their soma (Fig. 1, Table 2). Conversely, when analyzing the number of BrdU-IR cells in the DG, we found that spatial learning did not influence the survival of new cells born 2 or 4 months before training (Fig. 2a,b, Table 2; Group effect: $F_{(1,18)}=0.20, p=0.65$;
Age effect: $F_{(1,18)}=1.36, p=0.26$; Group by Age effect: $F_{(1,18)}=$ $0.06, p=0.80)$. We then determined whether learning affected the formation of dendritic spines, a key element in receiving inputs. The morphological analysis of 4-month-old neurons labeled with GFP revealed that spatial learning increases the number of spines (Fig. $2 c, d ; t_{(57)}=-2.17 ; p=0.033$ ).

We then wanted to determine whether learning was also regulating the dendritic development of developmentally generated neurons. To do so, we used the lentiviral vector, pTRIP $\Delta$ U3MND-Dsred2-WPRE, which labels all neurons. The lentivirus was injected 4 months before training, and animals were killed $1 \mathrm{~d}$ after the end of the behavioral procedure (Table 1, batch 3). By analyzing the morphological features of developmentally generated neurons of trained animals compared with home cage rats, we found no differences in the dendritic arborization (Table 3, Fig. 3), indicating that spatial learning specifically impacts the development of the dendritic arbor of mature adult-born neurons.

Thus, spatial learning increases the complexity of the dendritic arbor of new neurons even when they are mature. Since it is believed that newborn neurons are involved in memory processing when immature (Aimone et al., 2010; Deng et al., 2010), we examined whether mature adult-born neurons that have been shaped by learning are functionally relevant. To do so, we used a lesion approach allowing ablation of adult-born neurons within a specific time window.

Ablating mature adult-born neurons impacts spatial learning We used the antimitotic Ara-C (Doetsch et al., 1999b; Kokoeva et al., 2005). In a first step, the effects of a daily bilateral intracerebroventricular infusion of different doses of Ara-C for 1 week 

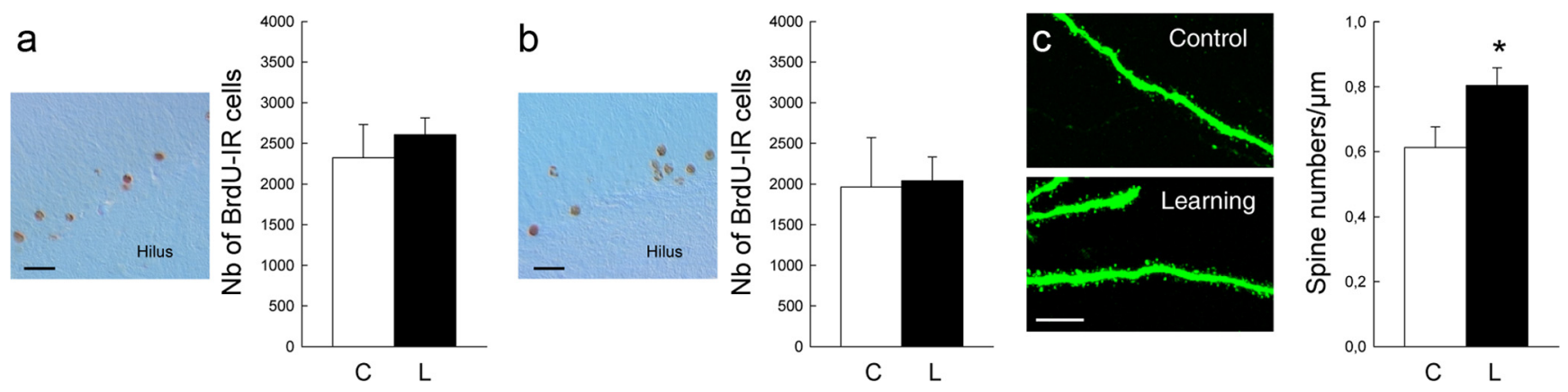

Figure 2. Influence of spatial learning on the survival and the number of spines of mature neo-neurons. $\boldsymbol{a}$, Left, Representative example of 2-month-old BrdU-IR cells. Scale bar, $20 \mu \mathrm{m}$. Right, Number of BrdU-IR cells. $\boldsymbol{b}$, Left, Representative example of 4-month-old BrdU-IR cells. Scale bar, $20 \mu \mathrm{m}$. Right, Number of BrdU-IR cells. $\boldsymbol{c}$, Left, Representative example of dendrites of 4-month-old neo-neurons. Scale bar, $10 \mu \mathrm{m}$. Right, Number of spines on dendrites of adult-born neurons generated 4 months before learning. C, Control ( 2 months: $n=6 ; 4$ months: $n=4) ; \mathrm{L}$, learning ( 2 months: $n=8 ; 4$ months: $n=6)$. ${ }^{*} p<0.05$ compared with age-matched control groups. Error bars indicate SEM.

Table 3. Influence of spatial learning on the dendritic arbor of granule neurons labeled with a Dsred lentivirus

\begin{tabular}{lccl}
\hline & \multicolumn{1}{l}{ Control } & \multicolumn{1}{l}{ Learning } & \multicolumn{1}{l}{ Significance } \\
\hline Dendritic length & $766.71 \pm 75.08$ & $731.96 \pm 33.14$ & $t_{(8)}=0.68, p=0.68$ \\
No. of nodes & $7.88 \pm 0.47$ & $7.00 \pm 0.34$ & $t_{(8)}=0.31, p=0.31$ \\
No. of endings & $8.94 \pm 0.75$ & $8.06 \pm 0.32$ & $t_{(8)}=0.31, p=0.31$ \\
Cell body area & $125.15 \pm 4.48$ & $121.72 \pm 8.30$ & $t_{(8)}=0.72, p=0.72$ \\
\hline
\end{tabular}

were examined (Table 1, Batch 4). BrdU was injected daily on the 3 last days of infusions, and animals were killed $24 \mathrm{~h}$ after the last BrdU pulse. Independently of the dose, Ara-C decreased cell proliferation as measured by the number of BrdU-IR cells (Fig. $4 a$; $\left.F_{(3,26)}=79.56 ; p<0.001\right)$. This result was confirmed by analyzing the number of proliferating doublecortin (Dcx)-labeled cells that are characterized by a lack of vertical dendrites [type A-B (Plümpe et al., 2006); Fig. $\left.4 b ; F_{(3,26)}=21.86 ; p<0.001\right]$. In contrast, Ara-C spared mature Dcx-labeled cells with vertical dendrites (Plümpe et al., 2006), indicating that Ara-C targeted prevalently dividing cells (Fig. $4 c ; F_{(3,26)}=2.28 ; p=0.1$ ). Then we verified that cell genesis returns to normal after the cessation of the treatment. Since neurogenesis in the subventricular zone is back to normal within 2 weeks (Doetsch et al., 1999a; Ma et al., 2006), we killed animals 2 weeks after the last Ara-C infusion (Table 1, Batch 5). We found that cell genesis in aCSF-infused animals (number of Ki67-IR cells, $6480 \pm 237.96$ ) was similar to that measured in Ara-C-infused animals $\left(6083 \pm 468.57 ; t_{(10)}=\right.$ $0.75 ; p=0.47)$.

In a next experiment, animals were infused with the lowest dose of Ara-C or aCSF and subsequently challenged 2 or 4 months later in the water maze (Table 1 , batches 9,10 ). We found that Ara-C delays learning at both delays (Fig. 5). Animals tested 2 months after Ara-C treatment were impaired on the second and third days of testing $\left(F_{(1,22)}=9.25 ; p<0.01\right)$, whereas performance was impaired during the first $3 \mathrm{~d}$ of training when animals were tested 4 months after Ara-C treatment $\left(F_{(1,17)}=7.97 ; p<\right.$ $0.001)$. For this delay, Ara-C and aCSF groups were similar on the first trial of the first testing day $\left(t_{(17)}=0.93 ; p=0.37\right)$, indicating that subsequent impairment was not due to noncognitive deficits. A more detailed analysis of the swim path (Wolfer and Lipp, 1992) highlighted that Ara-C animals were less efficient in learning to find the hidden platform compared with aCSF agematched controls. Indeed, the cumulative search error (Fig. $5 e, 2$ month delay: $F_{(1,22)}=6.43 ; p<0.02$; Fig. $5 f$, 4 month delay: $F_{(1,17)}=12.2 ; p<0.01$ ) and path efficiency index (Fig. $5 g, 2$ month delay: $F_{(1,22)}=6.65 ; p<0.02$; Fig. $5 h, 4$ month delay:
$\left.F_{(1,17)}=5.80 ; p<0.001\right)$ were impaired during the first training days.

In contrast, the swim speed of animals treated with Ara-C was similar to that measured in aCSF-infused animals (data not shown) (2 month delay: Group effect: $F_{(1,22)}=0.02, p=$ 0.88 ; Group by Trial by Day interaction: $F_{(15,360)}=1.29, p=$ 0.20 ; 4 month delay: Group effect: $F_{(1,17)}=0.15, p=0.69$; Group by Trial by Day interaction: $\left.F_{(15,255)}=0.54, p=0.92\right)$ confirming that Ara-C treatment did not induce motor deficits. At the end of training, we verified that Ara-C permanently and extensively depleted the number of cells that were born at the time of the infusion (Table 4; Group effect: $F_{(1,41)}=$ 131.33, $p<0.0001$; Age effect: $F_{(1,41)}=1.42, p=0.24$; Group by Age effect: $\left.F_{(1,41)}=1.75, p=0.19\right)$, while it spared proliferation at the time of training.

Finally, we examined the impact of depleting neurogenesis on spatial learning measured after a short delay. The rationale for doing that was based on the observation that, on one hand, spatial learning increases the complexity of the dendritic arbor of immature neurons (Tronel et al., 2010) and, on the other hand, these immature neurons are not activated by learning (Kee et al., 2007). To determine whether immature neurons are required for spatial learning, Ara-C- or aCSF-treated rats were challenged in the water maze 1 week after the end of the treatment. We found that memory abilities were preserved in Ara-C-infused animals (Fig. $6 a$, batch 11, latency: $F_{(1,22)}=0.10 ; p=0.75$; Fig. $6 b$, distance: $\left.F_{(1,22)}=0.010 ; p=0.90\right)$, although the number of BrdU-IR cells was decreased in these animals compared with aCSF-infused ones (Fig. $6 c ; t(22)=16.96 ; p<0.0001$ ).

Together, our results show that learning sculpts the dendritic arbor of mature neo-neurons that are functionally integrated into the dentate network.

\section{Discussion}

Together, our results indicate that there is no critical time window at immature stage for the sensitivity of the dendritic development of adult-born neurons relative to learning experience. Indeed, spatial learning sculpts their dendritic arbor even when adult-born neurons are several months of age. In addition, we found that these mature adult-born neurons are functionally integrated into the dentate network.

\section{Critical period during adult-born development}

It has been shown that, when immature, adult-born hippocampal neurons are highly plastic (Schmidt-Hieber et al., 2004; Ge et al., 2007) and that the animal's experience does determine the sur- 
a

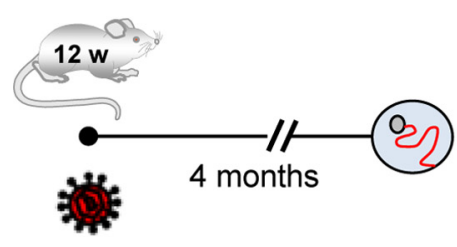

b

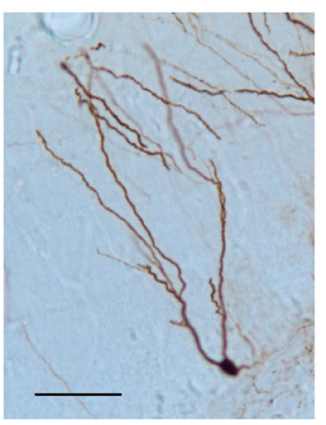

C

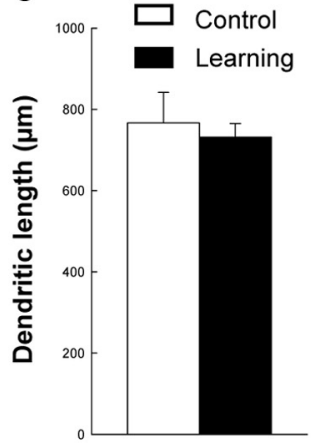

d

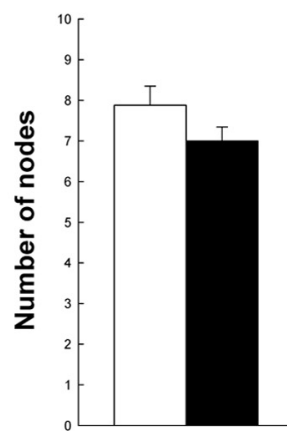

e

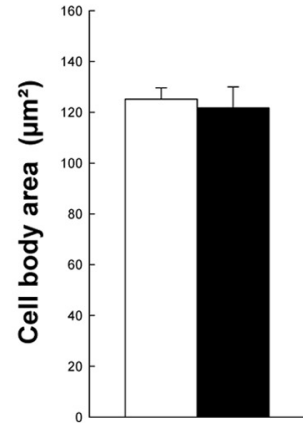

Figure 3. Influence of spatial learning on the dendritic arbor complexity of mature granule neurons. $\boldsymbol{a}$, Experimental design. $\boldsymbol{b}$, Representative example of granule neurons labeled with a Dsred retrovirus. Scale bar, $50 \mu \mathrm{m} . \boldsymbol{c}-\boldsymbol{e}$, Spatial learning does not change the dendritic length $(\boldsymbol{c})$, the number of nodes $(\boldsymbol{d})$, and the size of the cell bodies $(\boldsymbol{e})$ of granule neurons. Control $(n=5)$; Learning $(n=5)$. Error bars indicate SEM.

a

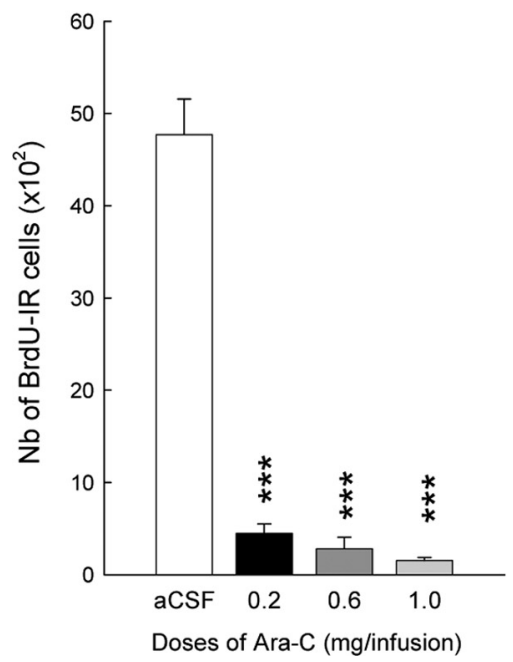

b

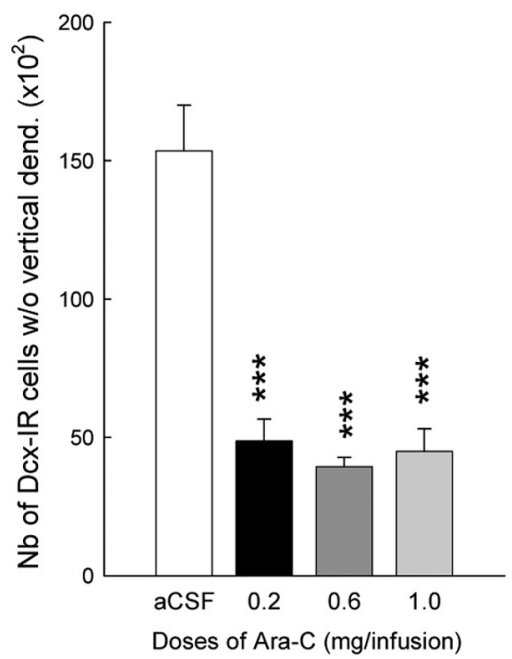

C

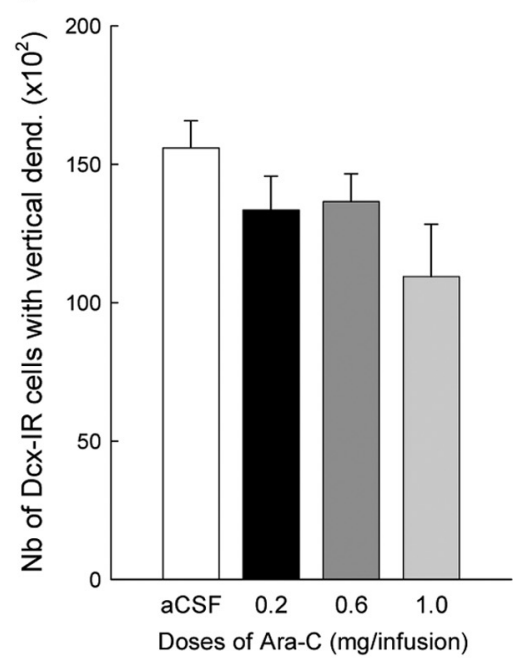

Figure 4. Ara-C infusion decreases the production of adult-born neurons. $\boldsymbol{a}, \boldsymbol{b}$, Ara-C decreases cell proliferation measured by the number of BrdU-IR cells ( $\boldsymbol{a})$ and the number of $D c x-I R$ cells without vertical dendrites $(\boldsymbol{b})$. $\boldsymbol{c}$, In contrast, Ara-C spares mature Dcx-labeled cells with vertical dendrites. aCSF: $n=10 ; \operatorname{AraC} 0.2: n=8 ; \operatorname{AraC} 0.6: n=5 ; \operatorname{AraC} 1: n=8$. The lowest efficient dose of Ara-C was used in subsequent experiments. ${ }^{* * *} p<0.001$ compared with aCSF-infused animals. Error bars indicate SEM.

vival of the new neurons. In particular, hippocampal-dependent learning promotes the survival of newborn cells generated 1 week before training, as a function of task difficulty. Trace eye blink conditioning and spatial learning (reference memory or delayed matching to place) exert a survival-promoting effect (Shors et al., 2012), whereas active shock avoidance and fear contextual memory are insufficient to change cell survival (Pham et al., 2005; Van der Borght et al., 2005; LopezFernandez et al., 2007). More recently, we have discovered that learning-induced survival of these immature neurons depends upon the elimination of youngest newborn cells at a specific developmental period (Drapeau et al., 2007; Dupret et al., 2007; Tronel et al., 2010). This homeostatic regulation of numbers of newly born neurons, similar to the selective stabilization process observed during development (for discussion, see Dupret et al., 2007), depends upon the activation of NMDA receptors (Tronel et al., 2010) most probably driven by learning-induced activity (Bruel-Jungerman et al., 2006).

Here, we show that cell survival of neurons born several months before learning was unchanged following training, a result expected since these cells were already integrated into the circuit at the time of training. These results indicate that learning regulates cell survival within a critical period during immature stage. Similarly, it has been shown in mice that the effects of an enriched environment on the survival of new neurons are restricted to an immature neuronal population aged 1-3 weeks (Tashiro et al., 2007).

In contrast, we document that there is no critical time window at immature stage for the sensitivity of neo-neuron dendritic development to environmental challenge. Indeed, spatial learning increased the dendritic length, the number of nodes and endings, the number of spines as well as the size of the soma. We have previously reported that, in rats, the dendritic arbor of adult-born neurons continue to develop over a period of 3 months [Tronel et al. (2010), their Table S2]. Thus, the present data indicate that, even at an older developmental stage, adult-born neurons are still plastic and responsive to learning by exhibiting dendritic growth. This sensitive period of adult-born neuron to learning experience is thus longer than that originally thought. Recently, in the olfactory bulb, the second main adult brain neurogenic area, adult-born granule neurons have been shown to undergo plasticity following odor enrichment when 2-3 months of age (Livneh and Mizrahi, 2011). Together, these data uncovered that the po- 
a

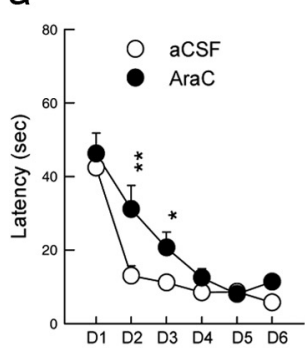

b

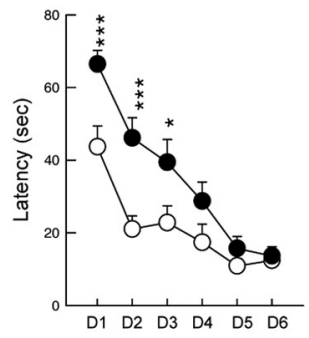

C

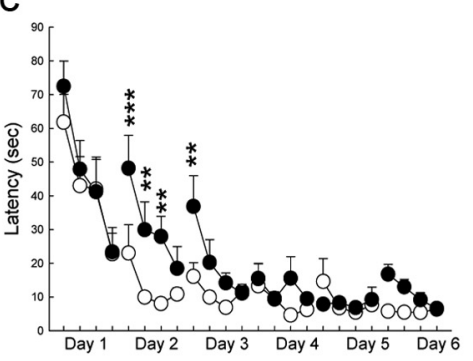

d

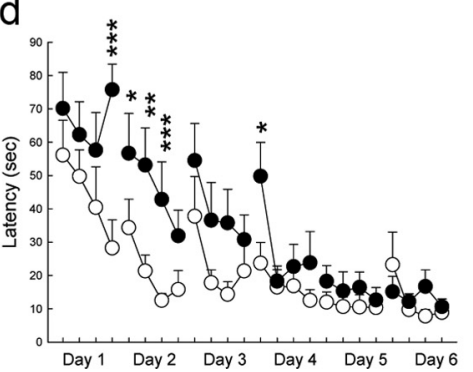

e

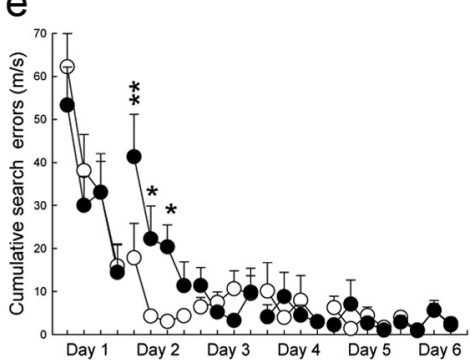

f

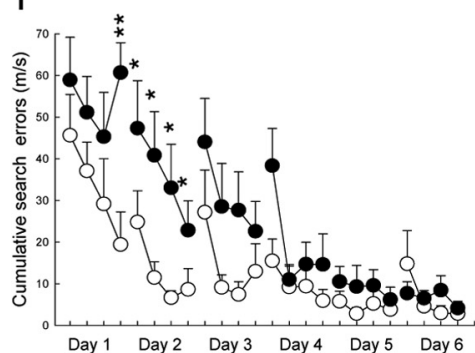

g

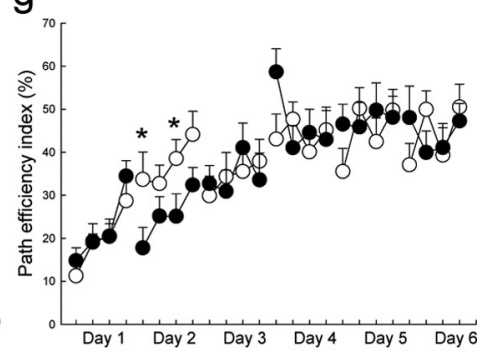

$\mathrm{h}$

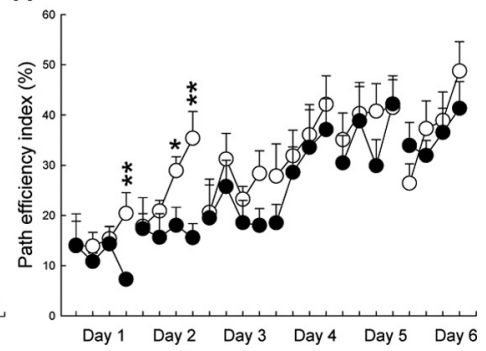

Figure 5. Ara-C infusion 2 (top) or 4 (bottom) months before training impairs spatial learning. $\boldsymbol{a}, \boldsymbol{b}$, Daily mean latencies. $\boldsymbol{c}, \boldsymbol{d}$, Mean latencies for four trials per day for 6 training days. $\boldsymbol{e}, \boldsymbol{f}$, Cumulative search error for four trials per day for 6 training days. $\boldsymbol{g}, \boldsymbol{h}$, Path efficiency index for four trials per day for 6 training days. Two month delay: aCSF, $n=6$; Ara-C $0.2, n=6$. Four month delay: aCSF, $n=13 ;$ Ara-C $0.2, n=13 .{ }^{*} p<0.05,{ }^{* *} p<0.01,{ }^{* * *} p<0.0001$ compared with age-matched aCSF control groups. Error bars indicate SEM.

Table 4. Influence of AraC treatment on cell genesis measured after the end of training

\begin{tabular}{lccl}
\hline Delay postinfusion & aCSF & Ara-C & Significance \\
\hline 2 months & & & \\
Nb BrdU-IR cells & $3083.08 \pm 347.87$ & $29.2 \pm 15.46$ & $t_{(24)}=9.48, p<0.0001$ \\
Nb KI67-IR cells & $2245 \pm 202.59$ & $1936 \pm 146.94$ & $t_{(24)}=-1.13, p=0.27$ \\
4 months & & & \\
Nb BrdU-IR cells & $2481.22 \pm 359.659$ & $60.00 \pm 40.99$ & $t_{(17)}=7.06, p<0.0001$ \\
Nb KI67-IR cells & $2000 \pm 151.13$ & $1779 \pm 222.04$ & $t_{(17)}=-0.80, p=0.43$ \\
\hline
\end{tabular}

tential for experience-dependent plasticity of adult-born neurons extends well into maturity.

However, these results raised the question whether developmentally generated neurons can be shaped under similar conditions. We addressed this issue, by using the lentiviral vector, pTRIPAU3-MND-Dsred2-WPRE, which labels all neurons. We found no differences in the dendritic tree between control and animals submitted to spatial learning 4 months after viral labeling. These results indicate that learning-induced changes on dendritic arbor are specific to neurons born during adulthood. To our knowledge, the only studies that examined the influence of learning on structural plasticity of dentate neurons reported a lack of effect (Rusakov et al., 1997) or only a transient increase in spine density or size (O'Connell et al., 2000; O'Malley et al., 2000). These results might seem surprising in the light of the abundant literature showing that learning influences the dendritic tree and synaptic density in other brain areas (Bailey and Kandel, 1993; Moser et al., 1994; Kleim et al., 1997; Rusakov et al., 1997; Moser, 1999; Leuner et al., 2003). Interestingly it has been recently shown that developmentally generated neurons (born at P7) are resistant to status epilepticus-induced remodeling, whereas adult-generated ones are vulnerable (Kron et al., 2010). To date, the degree of functional connectivity and plasticity of naive 2-month-old adult-generated neurons has been reported similar to that of neurons generated during development (Laplagne et al., 2006). Additional investigations are required to further explore the plasticity of adult-generated granule neurons and to which extent they share similarities with developmentally generated ones in response to environmental challenges.

\section{Functional integration of mature adult-born neurons}

Having shown that mature adult-born neurons are still plastic, we ascertain that they are functionally integrated into the dentate network by analyzing the impact of their loss on spatial learning. We took advantage of Ara-C that reversibly stops cell division and allows neurogenesis depletion within a given time window. Ara-C infusions were performed 2 or 4 months before training, to determine the role that would have been played by these mature adult-born neurons. We found that learning was delayed as impairment was observed only at the beginning of training when animals have to elaborate and learn to use a cognitive map. These deficits were not related to a disruption of ongoing neurogenesis since at the time of killing cell proliferation was back to normal. An alteration of synaptic plasticity can be ruled out since LTP and LTD impairments are rescued completely within 4 weeks after restoring adult neurogenesis (Massa et al., 2011). The deficits that we observed were not either due to ablation of subventricular zone progenitor cells or to nonspecific effects of AraC since animals tested for a shorter delay learned the task. Long-term Ara-C animals learned the task by the end of training, a result expected since only a small population of adult-born neurons was depleted (due to the time-limited infusion of Ara-C). Depleting them over several months might have led to more pronounced deficits as we have previously reported using a transgenic approach (Dupret et al., 2008). Overall, these results indicate that adult-born neurons generated several months before training are required for spatial learning. It has been proposed that, as they mature, adult-born neurons become less plastic and retire from the network (Alme et al., 2010). However, the present data do not support this hypothesis as mature adult-born neurons: (1) are still capable of learning-induced dendritic remodeling well after they have integrated into the dentate network, (2) are required for learning, and (3) do not become less responsive to learning experience with the passage of time (Ramirez-Amaya et al., 2006). 
a

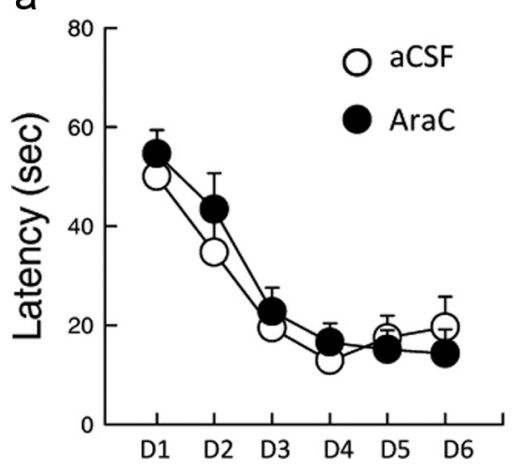

b

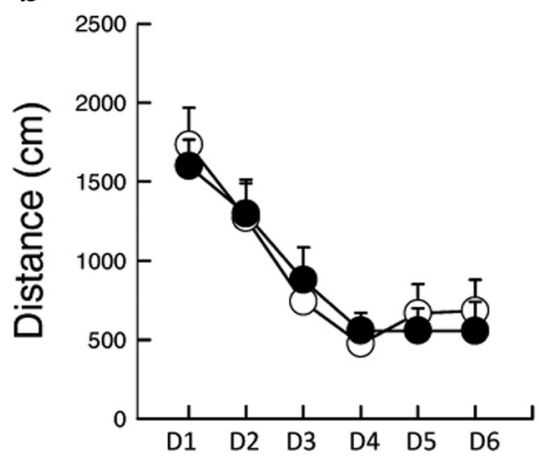

C

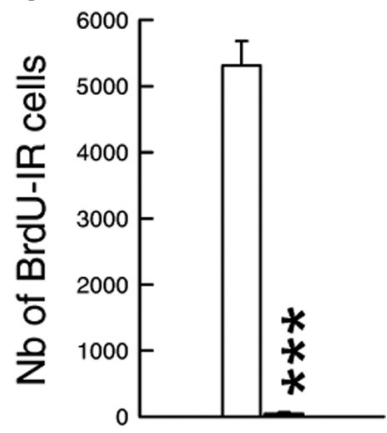

Figure 6. Ara-C infusion 1 week before training does not influence spatial learning and reduces the production of newly born cells. $\boldsymbol{a}$, Mean daily latencies. $\boldsymbol{b}$, Mean daily distance. $\boldsymbol{c}$, Number of BrdU-IR cells. aCSF, $n=10 ; \operatorname{AraC} 0.2, n=14$. ${ }^{* *} p<0.0001$ compared with age-matched aCSF control groups. Error bars indicate SEM.

\section{Time-dependent functional involvement of adult-born neurons}

Having shown that mature adult-born neurones are required for learning, a related key question is when newborn neurons become functionally relevant for hippocampal-dependent memory. Four- to 6-week-old adult-born neurons have been described to be necessary for spatial exploration, contextual fear conditioning, and novelty-evoked exploration (Denny et al., 2011; Sandoval et al., 2011). So far, there is no evidence that neurogenesis (at least cell survival) is influenced by these onetrial tasks. Thus, transient enhancement of synaptic plasticity observed in young adult-born neurons may contribute to these forms of memory.

The situation is more complex concerning spatial navigation in the water maze. By imaging new neurons using immediateearly gene products, it has been shown that new neurons are not recruited before 4 weeks of age (Kee et al., 2007). As a consequence, ablation of immature neurons with AraC failed to induce spatial learning deficits when 13- to 19-d-old cells were tagged, a result consistent with previous observations (Shors et al., 2002; Snyder et al., 2005; Goodman et al., 2010). However, when the new neurones reached 6 weeks of age, they were required in retrieving remote memory (Snyder et al., 2005; Trouche et al., 2009; Goodman et al., 2010). Thus, immature neurons are involved in the retention but not acquisition of the water maze task. Given that spatial learning shapes a particular set of new immature neurons, one can propose that these new neurones are "primed" or "tagged" during learning (and not involved in), a process allowing them once mature to contribute to update spatial memory when encountering a similar experience (Trouche et al., 2009). Interestingly, depleting immature adult-born olfactory neurons impairs retention but not acquisition of an associative olfactory task (Sultan et al., 2010) and are furthermore required for perceptual learning, an implicit form of learning in which discrimination between sensory stimuli is improved by previous experience (Moreno et al., 2009). Thus, primed or tagged immature new neurons may participate in the neural representation of the learned space or odor, which will be used on recall of the task.

In conclusion, we highlight for the first time that mature neoneurons are still capable of structural remodeling in response to learning and are functionally recruited into the memory network. This new dimension should provide novel directions for biological and computational studies that seek to understand the role of adult neurogenesis. Specifically, we propose that even "mature" neo-neurons provide an additional source of plasticity to the brain to process memory information.

\section{References}

Abrous DN, Koehl M, Le Moal M (2005) Adult neurogenesis: from precursors to network and physiology. Physiol Rev 85:523-569.

Aimone JB, Deng W, Gage FH (2010) Adult neurogenesis: integrating theories and separating functions. Trends Cogn Sci 14:325-337.

Alme CB, Buzzetti RA, Marrone DF, Leutgeb JK, Chawla MK, Schaner MJ, Bohanick JD, Khoboko T, Leutgeb S, Moser EI, Moser MB, McNaughton BL, Barnes CA (2010) Hippocampal granule cells opt for early retirement. Hippocampus 20:1109-1123.

Bailey CH, Kandel ER (1993) Structural changes accompanying memory storage. Annu Rev Physiol 55:397-426.

Bruel-Jungerman E, Davis S, Rampon C, Laroche S (2006) Long-term potentiation enhances neurogenesis in the adult dentate gyrus. J Neurosci 26:5888-5893.

Deng W, Aimone JB, Gage FH (2010) New neurons and new memories: how does adult hippocampal neurogenesis affect learning and memory? Nat Rev Neurosci 11:339-350.

Denny CA, Burghardt NS, Schachter DM, Hen R, Drew MR (2011) 4- to 6-week-old adult-born hippocampal neurons influence novelty-evoked exploration and contextual fear conditioning. Hippocampus. Advance online publication. Retrieved January 25, 2012. doi:10.1002/hipo.20964.

Döbrössy MD, Drapeau E, Aurousseau C, Le Moal M, Piazza PV, Abrous DN (2003) Differential effects of learning on neurogenesis: learning increases or decreases the number of newly born cells depending on their birth date. Mol Psychiatry 8:974-982.

Doetsch F, Caillé I, Lim DA, García-Verdugo JM, Alvarez-Buylla A (1999a) Subventricular zone astrocytes are neural stem cells in the adult mammalian brain. Cell 97:703-716.

Doetsch F, García-Verdugo JM, Alvarez-Buylla A (1999b) Regeneration of a germinal layer in the adult mammalian brain. Proc Natl Acad Sci U S A 96:11619-11624.

Drapeau E, Montaron MF, Aguerre S, Abrous DN (2007) Learning-induced survival of new neurons depends on the cognitive status of aged rats. J Neurosci 27:6037-6044.

Dupret D, Fabre A, Dobrössy M, Panetier A, Rodriguez JJ, Lemaire V, Oliet SHR, Piazza PV, Abrous DN (2007) Spatial learning depends on both the addition and removal of new hippocampal neurons. PLoS Biol 5:1683-1694.

Dupret D, Revest JM, Koehl M, Ichas F, De Giorgi F, Costet P, Abrous DN, Piazza PV (2008) Spatial relational memory requires hippocampal adult neurogenesis. PLoS One 3:e1959.

Farioli-Vecchioli S, Saraulli D, Costanzi M, Pacioni S, Cinà I, Aceti M, Micheli L, Bacci A, Cestari V, Tirone F (2008) The timing of differentiation of adult hippocampal neurons is crucial for spatial memory. PLoS Biol 6:e246.

Garthe A, Behr J, Kempermann G (2009) Adult-generated hippocampal neurons allow the flexible use of spatially precise learning strategies. PLoS One 4:e5464. 
Ge S, Yang CH, Hsu KS, Ming GL, Song H (2007) A critical period for enhanced synaptic plasticity in newly generated neurons of the adult brain. Neuron 54:559-566.

Goodman T, Trouche S, Massou I, Verret L, Zerwas M, Roullet P, Rampon C (2010) Young hippocampal neurons are critical for recent and remote spatial memory in adult mice. Neuroscience 171:769-778.

Gould E, Beylin A, Tanapat P, Reeves A, Shors TJ (1999) Learning enhances adult neurogenesis in the hippocampal formation. Nat Neurosci 2:260-265.

Kee N, Teixeira CM, Wang AH, Frankland PW (2007) Preferential incorporation of adult-generated granule cells into spatial memory networks in the dentate gyrus. Nat Neurosci 10:355-362.

Kempermann G, Kuhn HG, Gage FH (1997) More hippocampal neurons in adult mice living in an enriched environment. Nature 386:493-495.

Kempermann G, Gast D, Kronenberg G, Yamaguchi M, Gage FH (2003) Early determination and long-term persistence of adult-generated new neurons in the hippocampus of mice. Development 130:391-399.

Kleim JA, Vij K, Ballard DH, Greenough WT (1997) Learning-dependent synaptic modifications in the cerebellar cortex of the adult rat persist for at least four weeks. J Neurosci 17:717-721.

Kokoeva MV, Yin H, Flier JS (2005) Neurogenesis in the hypothalamus of adult mice: potential role in energy balance. Science 310:679-683.

Kron MM, Zhang H, Parent JM (2010) The developmental stage of dentate granule cells dictates their contribution to seizure-induced plasticity. J Neurosci 30:2051-2059.

Laplagne DA, Espósito MS, Piatti VC, Morgenstern NA, Zhao C, van Praag H, Gage FH, Schinder AF (2006) Functional convergence of neurons generated in the developing and adult hippocampus. PLoS Biol 4:e409.

Leuner B, Falduto J, Shors TJ (2003) Associative memory formation increases the observation of dendritic spines in the hippocampus. J Neurosci 23:659-665.

Livneh Y, Mizrahi A (2011) Experience-dependent plasticity of mature adult-born neurons. Nat Neurosci 15:26-28.

Lopez-Fernandez MA, Montaron MF, Varea E, Rougon G, Venero C, Abrous DN, Sandi C (2007) Upregulation of polysialylated neural cell adhesion molecule in the dorsal hippocampus after contextual fear conditioning is involved in long-term memory formation. J Neurosci 27:4552-4561.

Ma L, Yin M, Wu X, Wu C, Yang S, Sheng J, Ni H, Fukuda MN, Zhou J (2006) Expression of trophinin and bystin identifies distinct cell types in the germinal zones of adult rat brain. Eur J Neurosci 23:2265-2276.

Massa F, Koehl M, Wiesner T, Grosjean N, Revest JM, Piazza PV, Abrous DN, Oliet SH (2011) Conditional reduction of adult neurogenesis impairs bidirectional hippocampal synaptic plasticity. Proc Natl Acad Sci U S A 108:6644-6649.

Moreno MM, Linster C, Escanilla O, Sacquet J, Didier A, Mandairon N (2009) Olfactory perceptual learning requires adult neurogenesis. Proc Natl Acad Sci U S A 106:17980-17985.

Morris RG, Garrud P, Rawlins JN, O'Keefe J (1982) Place navigation is impaired in rats with hippocampal lesions. Nature 297:681-683.

Moser MB (1999) Making more synapses: a way to store information? Cell Mol Life Sci 55:593-600.

Moser MB, Trommald M, Andersen P (1994) An increase in dendritic spine density on hippocampal CA1 pyramidal cells following spatial learning in adult rats suggests the formation of new synapses. Proc Natl Acad Sci U S A 91:12673-12675.

O'Connell C, Gallagher HC, O’Malley A, Bourke M, Regan CM (2000) CREB phosphorylation coincides with transient synapse formation in the rat hippocampal dentate gyrus following avoidance learning. Neural Plast $7: 279-289$.

O'Malley A, O'Connell C, Murphy KJ, Regan CM (2000) Transient spine density increases in the mid-molecular layer of hippocampal dentate gyrus accompany consolidation of a spatial learning task in the rodent. Neuroscience 99:229-232.

Pham K, McEwen BS, Ledoux JE, Nader K (2005) Fear learning transiently impairs hippocampal cell proliferation. Neuroscience 130:17-24.
Piatti VC, Espósito MS, Schinder AF (2006) The timing of neuronal development in adult hippocampal neurogenesis. Neuroscientist 12:463-468.

Plümpe T, Ehninger D, Steiner B, Klempin F, Jessberger S, Brandt M, Römer B, Rodriguez GR, Kronenberg G, Kempermann G (2006) Variability of doublecortin-associated dendrite maturation in adult hippocampal neurogenesis is independent of the regulation of precursor cell proliferation. BMC Neurosci 7:77.

Ramirez-Amaya V, Marrone DF, Gage FH, Worley PF, Barnes CA (2006) Integration of new neurons into functional neural networks. J Neurosci 26:12237-12241.

Rusakov DA, Davies HA, Harrison E, Diana G, Richter-Levin G, Bliss TV, Stewart MG (1997) Ultrastructural synaptic correlates of spatial learning in rat hippocampus. Neuroscience 80:69-77.

Sandoval CJ, Martínez-Claros M, Bello-Medina PC, Pérez O, RamírezAmaya V (2011) When are new hippocampal neurons, born in the adult brain, integrated into the network that processes spatial information? PLoS One 6:e17689.

Schmidt-Hieber C, Jonas P, Bischofberger J (2004) Enhanced synaptic plasticity in newly generated granule cells of the adult hippocampus. Nature 429:184-187.

Sena-Esteves M, Tebbets JC, Steffens S, Crombleholme T, Flake AW (2004) Optimized large-scale production of high titer lentivirus vector pseudotypes. J Virol Methods 122:131-139.

Shors TJ, Townsend DA, Zhao M, Kozorovitskiy Y, Gould E (2002) Neurogenesis may relate to some but not all types of hippocampal-dependent learning. Hippocampus 12:578-584.

Shors TJ, Anderson ML, Curlik DM 2nd, Nokia MS (2012) Use it or lose it: how neurogenesis keeps the brain fit for learning. Behav Brain Res 227:450-458.

Snyder JS, Kee N, Wojtowicz JM (2001) Effects of adult neurogenesis on synaptic plasticity in the rat dentate gyrus. J Neurophysiol 85:2423-2431.

Snyder JS, Hong NS, McDonald RJ, Wojtowicz JM (2005) A role for adult neurogenesis in spatial long-term memory. Neuroscience 130:843-852.

Sultan S, Mandairon N, Kermen F, Garcia S, Sacquet J, Didier A (2010) Learning-dependent neurogenesis in the olfactory bulb determines longterm olfactory memory. FASEB J 24:2355-2363.

Tashiro A, Makino H, Gage FH (2007) Experience-specific functional modification of the dentate gyrus through adult neurogenesis: a critical period during an immature stage. J Neurosci 27:3252-3259.

Toni N, Laplagne DA, Zhao C, Lombardi G, Ribak CE, Gage FH, Schinder AF (2008) Neurons born in the adult dentate gyrus form functional synapses with target cells. Nat Neurosci 11:901-907.

Tronel S, Fabre A, Charrier V, Oliet SH, Gage FH, Abrous DN (2010) Spatial learning sculpts the dendritic arbor of adult-born hippocampal neurons. Proc Natl Acad Sci U S A 107:7963-7968.

Trouche S, Bontempi B, Roullet P, Rampon C (2009) Recruitment of adultgenerated neurons into functional hippocampal networks contributes to updating and strengthening of spatial memory. Proc Natl Acad Sci U S A 106:5919-5924.

Van der Borght K, Meerlo P, Luiten PG, Eggen BJ, Van der Zee EA (2005) Effects of active shock avoidance learning on hippocampal neurogenesis and plasma levels of corticosterone. Behav Brain Res 157:23-30.

van Praag H, Schinder AF, Christie BR, Toni N, Palmer TD, Gage FH (2002) Functional neurogenesis in the adult hippocampus. Nature 415:1030-1034.

Wolfer DP, Lipp HP (1992) A new computer program for detailed off-line analysis of swimming navigation in the Morris water maze. J Neurosci Methods 41:65-74.

Zhang CL, Zou Y, He W, Gage FH, Evans RM (2008) A role for adult TLX-positive neural stem cells in learning and behaviour. Nature 451:1004-1007.

Zhao C, Teng EM, Summers RG Jr, Ming GL, Gage FH (2006) Distinct morphological stages of dentate granule neuron maturation in the adult mouse hippocampus. J Neurosci 26:3-11. 